\title{
Pengaruh Kohesivitas dan Kepuasan Kerja terhadap Turnover Intention Karyawan
}

\section{The Effect of Cohesiveness and Job Satisfaction on Employees Turnover Intention}

\author{
Novia Annisa Putri ${ }^{1 *}$, Nurmala Katrina Pandjaitan ${ }^{2}$, Sadikin Kuswanto ${ }^{1}$ \\ ${ }^{1}$ Program Pascasarjana Manajemen dan Bisnis, Sekolah Bisnis, Institut Pertanian Bogor, Kampus Gunung Gede Bogor 16151 \\ ${ }^{2}$ Departemen Sains Komunikasi dan Pengembangan Masyarakat, Fakultas Ekologi Manusia, IPB Kampus Dramaga Bogor 16680
}

\begin{abstract}
$P T X$ is a major regional pharmaceutical company that develops and markets innovative products in Indonesia and other countries in South-East Asia. The high turnover rate in PT X indicates a further need to be explored about this condition and see if it is affected by employee cohesiveness and job satisfaction. This study uses quantitative approach with questionnaires that distributed to 120 head office employees with convenience sampling method. The result of structural equation modeling analysis shows that the better employee cohesiveness will increase the job satisfaction so that it can decrease the employee's desire to resign from the company. Cohesiveness has a significant positive effect on job satisfaction. In this case cohesiveness plays an important role in improving job satisfaction because having a cohesive group will affect employee satisfaction. Cohesiveness and job satisfaction have a significant negative impact on turnover intention. This suggests that cohesiveness and job satisfaction play an important role in decreasing employee intent turnover, even though the effect of cohesiveness is less than the effect of job satisfaction on turnover intention.
\end{abstract}

Keywords: cohesiveness, group, job satisfaction, turnover intention

\section{ABSTRAK}

PT X merupakan perusahaan farmasi regional utama yang mengembangkan dan memasarkan produk inovatif di Indonesia dan negara-negara lain di Asia Tenggara. Tingkat turnover yang tinggi di PT X menunjukkan perlunya untuk lebih lanjut ditelusuri mengenai kondisi tersebut dan melihat apakah hal itu dipengaruhi oleh kohesivitas karyawan dan kepuasan kerja. Penelitian ini menggunakan pendekatan kuantitatif dengan kuesioner yang disebarkan kepada 120 pegawai kantor pusat dengan metode convenience sampling. Hasil analisis pemodelan persamaan struktural menunjukkan bahwa kohesivitas karyawan yang lebih baik akan meningkatkan kepuasan kerja sehingga dapat menurunkan keinginan karyawan untuk mengundurkan diri dari perusahaan. Kohesivitas memiliki efek positif yang signifikan terhadap kepuasan kerja. Dalam hal ini kohesivitas memegang peranan penting dalam meningkatkan kepuasan kerja karena memiliki kelompok yang kohesif akan memengaruhi kepuasan kerja karyawan. Kohesivitas dan kepuasan kerja memiliki pengaruh negatif yang signifikan terhadap niat berpindah. Hal ini menunjukkan bahwa kekompakan dan kepuasan kerja berperan penting dalam menurunkan turnover intention karyawan, walaupun pengaruh kekompakan kurang dari pengaruh kepuasan kerja terhadap niat berpindah.

Kata Kunci: kelompok, kepuasan kerja, kohesivitas, turnover intention

*Corresponding author

Alamat e-mail: noviannisa.putri@gmail.com 


\section{PENDAHULUAN}

Karyawan merupakan aset penting bagi perusahaan dalam menjalankan operasional perusahaan. Namun begitu, suatu perusahaan yang telah berjalan dengan baik dapat menurun kinerjanya dikarenakan perilaku karyawan yang kerap kali terjadi. Salah satu perilaku karyawan yang mengganggu kinerja perusahaan adalah keinginan berpindah (turnover intention) yang berujung pada keputusan karyawan untuk meninggalkan pekerjaannya. Isu karyawan berpindah (turnover) saat ini masih menjadi suatu hal yang mengkhawatirkan bagi perusahaan. Meskipun pada umumnya kepindahan karyawan dianggap biasa, tapi bagi perusahaan hal ini sangat merugikan.

Di dunia, fenomena turnover sudah tidak lagi menjadi hal yang asing. Berdasarkan hasil penelitian Elkjaer dan Filmer (2015), rata-rata tren turnover, baik voluntary maupun involuntary tahun 2011-2014 mengalami peningkatan, khususnya di Brazil dan Amerika Serikat. Dalam hal industri, di penelitian tersebut juga memerlihatkan bahwa industri barang konsumsi (consumer goods) cenderung memiliki tren voluntary turnover cukup tinggi dibandingkan industri energi dan life sciences. Sementara itu, fenomena turnover di Indonesia juga cukup tinggi, yakni 8,75 persen dari seluruh industri, tertinggi pada industri jasa keuangan yakni 12,6 persen diikuti dengan industri life sciences yakni 11,0 persen (Mercer 2016).

Umumnya, timbulnya turnover diawali dengan adanya niat untuk berhenti bekerja (turnover intention) dari karyawan dan faktor kepuasan kerja menjadi faktor yang paling memengaruhi kecenderungan dan keputusan karyawan untuk keluar dari tempat kerjanya. Menurut Rageb et al. (2013), kepuasan kerja memiliki dampak yang lebih besar terhadap turnover intention dibandingkan dengan kinerja pekerjaan atau komitmen organisasi. Timbulnya ketidakpuasan kerja dapat terjadi sebagai akibat dari tidak terpenuhinya kebutuhan, harapan atau tujuan yang menjadi motivasi karyawan, hingga akhirnya dapat menimbulkan turnover intention. Salah satu kebutuhan karyawan yang penting adalah adanya kebutuhan afiliatif dan sumber penting bagi kepuasan kebutuhan tersebut bersumber dari sebuah kelompok yang kohesif (Kerr dan Jernier 1978).

PT X merupakan perusahaan yang termasuk dalam 10 besar perusahaan farmasi nasional. Saat ini PT X dan anak perusahaannya memekerjakan lebih dari 4.000 orang karyawan. Adanya perkembangan bisnis di industri farmasi, menuntut PT X untuk memberikan layanan dan kinerja yang optimal dengan didukung sumber daya manusia yang berkualitas. Namun begitu, tingkat voluntary turnover keseluruhan di PT X dapat dikatakan cukup tinggi. Berdasarkan data karyawan PT X Maret 2016-Maret 2017, di tingkat voluntary turnover sebesar 23,76 persen dari tingkat turnover keseluruhan yang sebesar 35,77 persen.

Adanya tingkat turnover yang berada di atas 10 persen menunjukkan perlunya ditelusuri lebih lanjut mengenai kondisi karyawan di PT X, apakah turnover yang tinggi tersebut sejalan dengan turnover intention yang dirasakan oleh karyawan. Hal ini dikarenakan turnover karyawan yang tinggi dapat menyebabkan kerugian moril pada pegawai perusahaan karena dapat menimbulkan turnover intention pada pegawai lain yang masih bertahan di perusahaan. Saat ada karyawan yang keluar, maka ada posisi yang kosong dan harus segera ada yang menggantikan. Selama posisi tersebut lowong, maka ada karyawan lain yang harus menggantikan dan bisa mengakibatkan tugas menumpuk dan terbengkalai. Ini akan memengaruhi motivasi, semangat kerja, serta kinerja karyawan. Karyawan yang sebelumnya tidak memikirkan pencari pekerjaan baru dapat akhirnya berpikiran untuk mencari pekerjaan lain dan berakibat munculnya turnover intention. Selain itu, saat terjadi turnover, perusahaan akan merekrut karyawan baru dan bagi sebagian karyawan lama hal ini dapat menimbulkan kesulitan karena harus beradaptasi dan membangun komunikasi dari awal dengan karyawan baru. Proses adaptasi dan komunikasi yang tidak berjalan dengan baik akan berpotensi menimbulkan konflik di antara karyawan yang dapat memicu keinginan pegawai untuk keluar dari perusahaan dan mencari alternatif pekerjaan di tempat lain (Mobley 2011).

Adanya hal-hal negatif yang dapat menimbulkan konflik dan ketidakpuasan seorang karyawan tersebut dapat menyebabkan karyawan memilih melakukan turnover, karena tidak 
merasa nyaman dengan suasana kelompok kerjanya. Sementara, kenyamanan adalah hal yang utama bagi seorang karyawan, terutama bagi karyawan yang tidak menganggap gaji sebagai prioritas. Hal ini juga diungkapkan oleh DeCotiis dan Summers (1987) bahwa individu masuk ke sebuah organisasi dengan kebutuhan tertentu, keinginan, keterampilan, dan berharap untuk menemukan sebuah lingkungan kerja di mana mereka dapat memanfaatkan kemampuan mereka dan memenuhi banyak kebutuhan dasar mereka. Organisasi yang memenuhi persyaratan tersebut, salah satunya ditandai dengan adanya rasa kohesif di antara anggota organisasi. Jika karyawan tidak lagi merasa nyaman, umumnya mereka akan mencari kenyamanan di tempat yang lain dan hal ini menimbulkan adanya turnover intention.

Beberapa penelitian terdahulu membahas hubungan mengenai kohesivitas, kepuasan kerja, dan turnover intention secara terpisah. Steinhardt et al. (2003) menemukan bahwa kohesivitas berpengaruh tidak langsung dengan kepuasan. Sementara itu Mudrack (1989), Bartkus et al. (1997), dan Urien et al. (2016) menemukan bahwa kohesivitas memiliki pengaruh yang kuat dengan kepuasan kerja. Selanjutnya, beberapa penelitian sebelumnya menemukan bahwa kepuasan kerja berpengaruh negatif dengan turnover intention (Randhawa 2007, Morrison 2008, dan Yin-Fah et al. 2010, Zhang dan Feng 2011, serta Kreitner dan Kinicki 2014). Sementara itu, Abdillah (2012) menemukan bahwa kuatnya tingkat turnover intention akan diikuti kohesivitas kelompok yang rendah dan sebaliknya, tingkat intensi turnover yang lemah akan diikuti tingkat kohesivitas kelompok yang tinggi. Hal yang bertentangan dinyatakan oleh Hausknecht et al. (2009) yang menemukan bahwa efek yang terjadi di voluntary turnover tidak bergantung pada kohesivitas kelompok. Penelitian yang menggabungkan ketiga variabel yang akan dibahas dalam penelitian pernah dilakukan oleh Septiani (2015). Dari hasil analisis regresi yang dilakukan, hasil penelitian ini menemukan bahwa terdapat intensi turnover kategori sedang pada pemanen di PT Kencana Sawit Indonesia, dan kepuasan kerja serta kohesivitas kelompok mempengaruhi negatif secara signifikan terhadap intensi turnover pemanen.

Berdasarkan masalah, tujuan, dan landasan teoritis, serta adanya perbedaan hasil dari beberapa penelitian terdahulu, maka dapat disimpulkan bahwa penelitian ini memiliki kesamaan variabel terikat dan variabel bebas yang diteliti sehingga hasil penelitian ini dapat memperkuat temuan yang sesuai dengan sudah ada sebelumnya. Namun begitu, penelitian ini memiliki perbedaan dari segi obyek penelitian, alat analisis dan indikator-indikator yang digunakan untuk mengukur setiap variabel. Hipotesis yang diajukan dalam penelitian ini adalah diduga kohesivitas berpengaruh terhadap kepuasan kerja (H1), kepuasan kerja berpengaruh terhadap turnover intention $(\mathrm{H} 2)$, dan kohesivitas berpengaruh terhadap turnover intention $(\mathrm{H} 3)$.

\section{METODE PENELITIAN}

Penelitian ini dilakukan di PT X. Pemilihan lokasi dilakukan secara purposive dengan mempetimbangkan kondisi perusahaan yang mengalami turnover yang tinggi. Kegiatan pengambilan data dilaksanakan mulai bulan Mei 2017 sampai dengan Juni 2017. Jenis data dalam penelitian ini merupakan data primer dan data sekunder. Data primer didapatkan dari kuesioner yang diberikan kepada responden serta wawancara dengan pihak perusahaan, yakni manajer SDM. Sementara data sekunder diperoleh dari laporan tahunan perusahaan, buku-buku teks ilmiah, dan hasil penelitian terdahulu, seperti jurnal, tesis, dan disertasi.

Pengambilan sampel dalam penelitian ini dilakukan dengan metode purposive sampling. Responden dipilih dengan kriteria masa kerja sekurang-kurangnya enam bulan, karena karyawan yang telah melewati masa kerja enam bulan dinilai sudah memunyai sikap terhadap lingkungan kerjanya. Selain itu, responden terdiri dari karyawan dengan jabatan staf, supervisor, dan manajer. Jumlah responden dibatasi berdasarkan persyaratan analisis yang digunakan dalam penelitian ini yaitu structural equation model (SEM). Jumlah responden yang diteliti pada penelitian ini adalah 120 orang, dimana jumlah tersebut didasarkan pada kompleksitas model dan karakteristik model pengukuran dasar yang diacu pada Hair et al. (2010). Menurut Hair et al. (2010), model dengan jumlah konstruk kurang dari lima dengan jumlah indikator pada tiap konstruknya lebih dari tiga, memerlukan jumlah minimum sampel sebanyak 100.

Jurnal Manajemen dan Organisasi (JMO),

Vol. 9, No. 1, April 2018, Hal. 35-44 
Variabel terikat dalam penelitian ini adalah kepuasan kerja dan turnover intention, sedangkan variabel bebas adalah kohesivitas. Setiap variabel diukur dengan menggunakan kuesioner. Carron et al. (2009) mendefinisikan kohesivitas kelompok sebagai proses dinamis yang terlihat melalui kecenderungan kelekatan dan kesatuan kelompok dalam pemenuhan tujuan dan atau kepuasan kebutuhan afeksi anggota kelompok. Variabel kohesivitas kelompok diukur dengan menggunakan total 16 pernyataan yang mengacu pada group environment questionnaire (GEQ) milik Carron et al. (1985) dengan memodifikasi pertanyaan dalam kuesioner sesuai dengan obyek penelitian. Setiap pernyataan diukur dengan skala Likert mulai dari "sangat tidak setuju" (1) sampai ke "sangat setuju" (5). Indikator Attraction to the Group Social (ATGS) diukur dengan mengajukan lima pernyataan untuk melihat sejauh mana ketertarikan individu menjadi anggota kelompok dalam aspek sosial. Indikator Attraction to the Group Task (ATGT) diukur untuk melihat sejauh mana ketertarikan individu menjadi anggota dalam aspek tugas, dengan mengajukan empat pernyataan. Indikator Group Integration Social (GIS) diukur dengan empat pernyataan untuk melihat persepsi anggota mengenai kekompakan atau integrasi kelompok dalam aspek sosial. Indikator Group Integration Task (GIT) diukur dengan lima pernyataan untuk melihat persepsi anggota mengenai kekompakan atau integrasi kelompok dalam aspek tugas.

Kepuasan kerja merupakan kondisi kepuasan emosional yang berasal dari penilaian seseorang terhadap pekerjaan atau pengalaman kerjanya (Colquitt et al. 2013). Variabel kepuasan kerja, akan diukur dengan indikator yang dikembangkan oleh Colquitt et al. (2013), yakni kepuasan akan pembayaran, promosi, atasan, rekan kerja, dan pekerjaan itu sendiri. Pernyataan dalam kuesioner disusun berdasarkan kesesuaian dengan indikator yang digunakan serta obyek penelitian. Total pernyataan dalam variabel ini adalah 20 pernyataan dan empat pertanyaan terbuka, dengan masing-masing indikator terdiri dari empat pernyataan. Setiap pernyataan diukur dengan skala Likert mulai dari "sangat tidak puas" (1) sampai ke "sangat puas" (5).

Menurut Lum et al. (2016) turnover intention adalah keinginan seseorang untuk keluar dari organisasi atau perusahaan, mengevaluasi mengenai posisi seseorang saat ini, berkenaan dengan ketidakpuasan, yang dapat memicu keinginan seseorang untuk keluar dan mencari pekerjaan lain. Variabel turnover intention diukur dengan menggunakan empat indikator yang diadaptasi dari penelitian terdahulu (Lum et al. 2016, Hom et al. 2012) untuk menunjukkan niat turnover responden. Pada variabel ini terdiri dari lima pernyataan yang mewakili empat indikator. Pernyataan satu dan dua adalah ukuran dari pertimbangan responden akan perusahaan tempatnya bekerja dan pernyataan tiga adalah ukuran dari pertimbangan responden akan keluar dari profesi kerjanya saat ini (Lum et al. 2016). Pernyataan empat dan lima adalah hal yang memberatkan seseorang untuk tinggal atau keluar (Hom et al. 2012). Pernyataan tersebut dilihat dari pertimbangan responden akan faktor personal yang memengaruhi niat mereka untuk meninggalkan pekerjaan mereka dan pertimbangan akan faktor-faktor yang berhubungan dengan pekerjaan. Pertanyaan dalam kuesioner untuk bagian variabel turnover intention, diacu dari Lum et al. (2016) dan Hom et al. (2012) dengan memodifikasi pernyataan agar sesuai dengan obyek penelitian. Setiap pernyataan diukur dengan skala Likert mulai dari "sangat tidak setuju" (1) sampai ke "sangat setuju" (5).

Data kuantitatif yang di dapat dari kuesioner diolah menggunakan aplikasi Microsoft Excell 2010 dan LISREL 8.8. Pembuatan tabel frekuensi untuk melihat data awal responden masing-masing variabel secara tunggal menggunakan aplikasi Microsoft Excell 2010 dan LISREL 8.8 digunakan untuk analisis SEM.

\section{HASIL DAN PEMBAHASAN}

\section{Karakteristik responden}

Dari hasil penelitian menggunakan kuesioner, responden yang merupakan karyawan PT $\mathrm{X}$ mayoritas berjenis kelamin laki-laki sebesar 67,5 persen dan perempuan sebesar 32,5 persen. Untuk usia responden, mayoritas berada pada kelompok usia $\leq 25$ tahun sebesar 55 persen, 
diikuti usia 26-35 tahun 35,8 persen dan di atas 35 tahun sebesar 9,2 persen. Masa kerja responden paling banyak berada pada kategori 1-3 tahun dengan persentase 80 persen, diikuti 46 tahun sebesar 14,2 persen, $\geq 10$ tahun sebesar 3,3 persen, dan 7-9 tahun sebesar 2,5 persen. Tingkat pendidikan responden mayoritas $\geq$ sarjana sebesar 60,8 persen dan $<$ sarjana sebesar 39,2 persen.

\section{Hasil analisis statistik}

Tingkat signifikansi hubungan antar variabel, baik dimensi dengan variabel laten maupun antar variabel laten, digunakan uji-t dengan tingkat signifikansi $\alpha=0,05(\operatorname{t} \alpha / 2=1,96)$. Sementara itu, nilai estimasi faktor muatan model (standardized loading factor) digunakan untuk mengukur besar pengaruh antar variabel laten atau bobot antara indikator ke variabel laten, dengan nilai maksimum 1. Hasil pengujian didapatkan seperti terlihat pada Gambar 1 untuk uji-t dan Gambar 2 sebagai nilai estimasi faktor muatan model. Pada Gambar 1 dapat dilihat bahwa semua hubungan, baik dimensi dengan variabel laten maupun antar variabel laten, meunjukkan hasil signifikan karena memiliki nilai t-hitung lebih dari 1,96.

Variabel kohesivitas terdiri dari empat dimensi yaitu attraction to the group social (ATGS), attraction to the group task (ATGT), group integration social (GIS), dan group integration task (GIT). Berdasarkan Gambar 2, diketahui dimensi GIT memiliki nilai koefisien faktor muatan (SLF) paling tinggi yakni sebesar 0,97. Hal ini berarti dalam penelitian ini variabel kohesivitas paling besar dicirikan oleh dimensi GIT. Hal ini menunjukkan bahwa keyakinan dan persepsi yang masing-masing anggota pegang tentang tim dalam aspek tugas menjadi faktor yang paling diperhitungkan dalam mengukur kohesivitas.

Variabel kepuasan kerja terdiri dari lima dimensi yaitu, pembayaran (S1), promosi (S2), pekerjaan itu sendiri (S3), atasan (S4) dan rekan kerja (S5). Berdasarkan Gambar 2 pengolahan variabel kepuasan kerja dilihat dari nilai faktor muatannya, dimensi S5 memiliki nilai faktor muatan paling tinggi yakni sebesar 0,88 .

Hal ini berarti variabel kepuasan kerja paling besar dicirikan oleh dimensi rekan kerja. Hal ini juga menunjukkan bahwa perasaan karyawan tentang teman sekerja mereka, dan sampai sejauh mana rekan sekerja bersahabat, kompeten, dan mendukung, menjadi faktor yang paling diperhitungkan dalam mengukur kepuasan kerja responden.

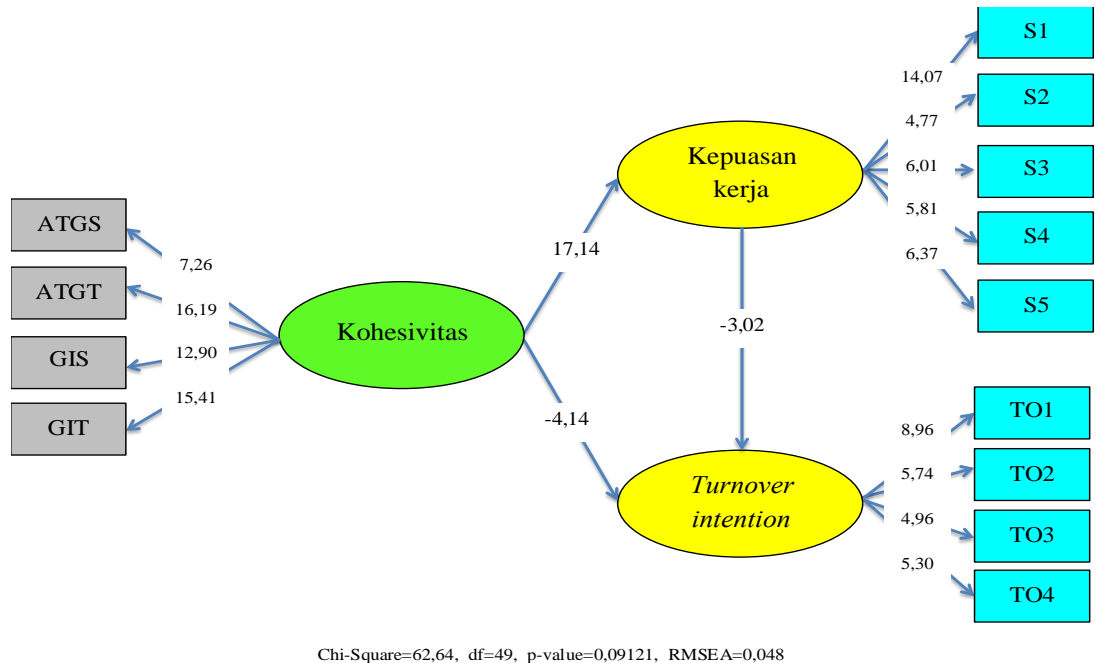

Gambar 1. Nilai uji signifikansi (T-test) model pengukuran 
Variabel turnover intention terdiri dari empat dimensi, yaitu berpikir untuk keluar dari organisasi (TO1), berpikir untuk keluar dari jalur karir (TO2), pertimbangan faktor personal (TO3), dan pertimbangan faktor pekerjaan (TO4). Berdasarkan Gambar 2 dimensi TO2 memiliki nilai faktor muatan paling tinggi yakni sebesar 0,88 . Hal ini berarti variabel turnover intention paling besar dicirikan oleh dimensi berpikir untuk keluar dari jalur karir. Hal ini menunjukkan bahwa perasaan karyawan tentang pertimbangan responden keluar dari profesi kerjanya saat ini, dimana responden ingin keluar dari perusahaan karena memilih mencari jalur karir lain, menjadi faktor yang paling diperhitungkan dalam mengukur keinginan responden untuk keluar dari perusahaannya (turnover intention).

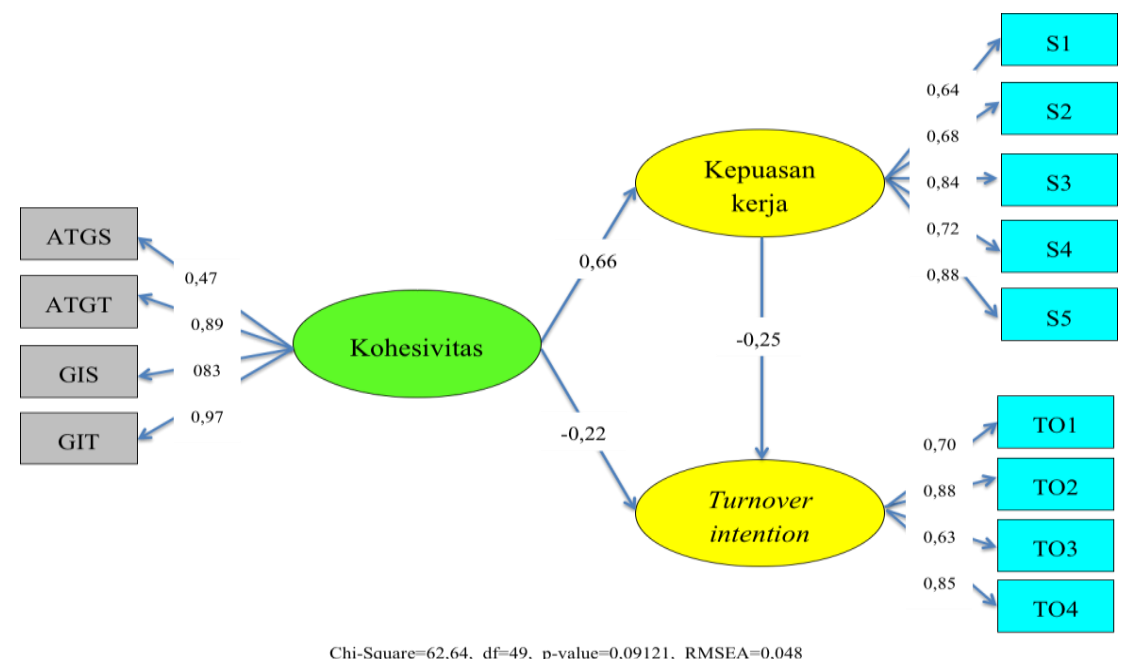

Gambar 2. Diagram nilai estimasi faktor muatan model pengukuran

Pengolahan data dengan menggunakan SEM menunjukkan hasil path diagram (Gambar 2) yang merupakan keluaran dari perangkat lunak LISREL 8.8 dapat dirangkum pada Tabel 1 untuk melihat hasil uji dari hipotesis yang diajukan.

Jurnal Manajemen dan Organisasi (JMO),

Vol. 9, No. 1, April 2018, Hal. 35-44

Tabel 1. Hasil estimasi model SEM

\begin{tabular}{|c|c|c|c|c|}
\hline \multirow{2}{*}{ Variabel laten } & \multicolumn{2}{|c|}{$\begin{array}{l}\text { Standardized loading } \\
\text { factor }\end{array}$} & \multirow{2}{*}{$|t-h i t|>1.96$} & \multirow{2}{*}{ Kesimpulan } \\
\hline & Langsung & $\begin{array}{c}\text { Tidak } \\
\text { langsung }\end{array}$ & & \\
\hline Kohesivitas $\rightarrow$ Kepuasan kerja & 0.66 & - & 17.14 & Signifikan \\
\hline Kohesivitas $\rightarrow$ turnover intention & -0.22 & - & 4.14 & Signifikan \\
\hline $\begin{array}{l}\text { Kepuasan kerja } \rightarrow \text { turnover } \\
\text { intention }\end{array}$ & -0.25 & - & 3.02 & Signifikan \\
\hline Kohesivitas $\rightarrow$ turnover intention & - & -0.17 & 11.09 & Signifikan \\
\hline
\end{tabular}

\section{Pengaruh kohesivitas terhadap kepuasan kerja}

Berdasarkan Tabel 1, hasil uji-t antara variabel kohesivitas dan kepuasan kerja diperoleh t-hitung sebesar 17,14. Nilai t-hitung>t-tabel maka $\mathrm{H}_{1}$ diterima. Hasil pengujian hipotesis menunjukkan bahwa kohesivitas berpengaruh secara langsung positif signifikan terhadap kepuasan kerja sebesar 0,66 , artinya semakin baik kohesivitas maka semakin meningkatkan kepuasan kerja karyawan. Hal ini sejalan dan memperkuat beberapa hasil penelitian terdahulu seperti penelitian dari Bartkus et al. (1997), dan Urien et al. (2016), yang menyatakan bahwa kohesivitas memiliki hubungan yang kuat dengan kepuasan kerja.

Steinhardt et al. (2003) menyatakan bahwa penjelasan yang mungkin untuk hubungan kohesi kelompok dan kepuasan kerja adalah bahwa kohesivitas menyiratkan kepuasan dengan satu aspek pekerjaan, kelompok, dan lebih mungkin bahwa kepuasan kerja akan lebih besar bagi mereka yang puas dengan kelompok mereka. Namun begitu, hasil penelitiannya menunjukkan 
bahwa hubungan langsung kohesi kelompok dengan kepuasan kerja tidak signifikan secara langsung tetapi berhubungan secara tidak langsung dengan kepuasan kerja melalui stres kerja. Hasil ini berbeda dengan penelitian sebelumnya yang telah menemukan bahwa kohesi kelompok dan kepuasan kerja saling terkait (Mudrack 1989). Perbedaan hasil ini terjadi dikarenakan adanya perbedaan cara di mana kohesi kelompok dioperasionalkan. Mudrack (1989) meneliti menggunakan instrumen yang terutama menilai kohesi kelompok sebagai atraksi interpersonal dalam kelompok.

Dalam penelitian dan pengukuran kohesivitas, Mudrack (1989) menyarankan untuk meneliti kohesivitas di luar konseptualisasi kohesivitas dalam hal daya tarik kelompok dan beralih ke arah konseptualisasi kohesivitas sebagai komitmen tugas kelompok, agar lebih membangun hubungan dengan hasil perilaku seperti produktivitas. Dengan demikian, hasil yang bertentangan diperoleh dengan pengukuran yang berbeda, dan hal ini menunjukkan bahwa cara di mana kohesi kelompok diukur dapat menentukan apakah hubungan dengan kepuasan kerja ditemukan. Steinhardt et al. (2003) menjelaskan lebih jauh bahwa ketika kohesi kelompok didefinisikan sebagai atraksi interpersonal dalam kelompok, membuat lebih mungkin terkait dengan hasil subjektif seperti kepuasan kerja daripada hasil perilaku. Ketika kohesi kelompok didefinisikan sebagai komitmen terhadap tugas kelompok, membuat kohesivitas terkait dengan hasil perilaku seperti produktivitas.

\section{Pengaruh kepuasan kerja terhadap turnover intention}

Berdasarkan Tabel 1, hasil uji-t antara variabel kepuasan kerja dan turnover intention, diperoleh t-hitung sebesar 3,02. Nilai t-hitung>t-tabel maka $\mathrm{H}_{2}$ diterima. Hasil pengujian hipotesis menunjukkan bahwa kepuasan kerja berpengaruh secara langsung negatif signifikan terhadap turnover intention. Nilai estimasi faktor muatan model sebesar $-0,25$, artinya semakin baik atau semakin terpenuhinya kepuasan kerja karyawan maka akan semakin menurunkan niat untuk berpindah (turnover intention) karyawan PT X. Hal ini sejalan dan memperkuat hasil beberapa penelitian terdahulu. Penelitian Randhawa (2007), Morrison (2008), dan Yin-Fah et al. (2010), menemukan bahwa semakin tinggi tingkat kepuasan kerja seseorang, maka semakin rendah intensitasnya untuk meninggalkan pekerjaannya. Mereka yang kepuasan kerjanya lebih rendah, mudah untuk meninggalkan perusahaan dan mencari kesempatan di perusahaan lain. Studi lainnya yang dikemukakan Zhang dan Feng (2011) juga menunjukkan bahwa kepuasan kerja dan turnover intention mempunyai hubungan negatif. Hasil ini berbeda dengan hasil penelitian Hapsari (2014) dan Witasari (2009) yang menemukan bahwa tidak ada pengaruh yang signifikan antara kepuasan kerja terhadap turnover intention.

Menurut Robbins dan Judge (2015), kepuasan kerja memiliki sebuah koneksi lingkungan juga. Jika iklim dalam suatu tempat kerja, di mana salah satu pekerja memiliki kepuasan kerja yang rendah, akan ada efek yang menular. Manajer perlu memertimbangkan pola kepuasan kerja dari rekan-rekan kerja saat menugaskan para pekerja baru untuk sebuah area karena hal ini. Selain itu, hubungan kepuasan dan perputaran juga dipengaruhi oleh alternatif prospek kerja. Jika seorang pekerja dihadapkan dengan sebuah tawaran pekerjaan yang tidak diinginkan, ketidakpuasan kerja menjadi kurang prediktif untuk perputaran karena pekerja itu lebih mungkin beralih pada perputaran pekerja saat peluang pekerjaan banyak karena para pekerja menilai mudah untuk berpindah.

\section{Pengaruh kohesivitas terhadap turnover intention}

Pengaruh kohesivitas terhadap turnover intention dapat dilihat secara langsung dan tidak langsung. Berdasarkan Tabel 1, hasil uji-t secara langsung antara variabel kohesivitas dan turnover intention, diperoleh t-hitung sebesar 4,14. Nilai t-hitung $>\mathrm{t}$-tabel sehingga $\mathrm{H}_{3}$ diterima. Hasil ini juga menunjukkan variabel kohesivitas berpengaruh negatif secara langsung terhadap turnover intention dengan nilai estimasi faktor muatan model sebesar -0,22. Hal ini diartikan bahwa semakin baik kohesivitas maka semakin menurunkan turnover intention. Hasil penelitian ini sejalan dan mendukung hasil penelitian Abdilllah (2012), yang menemukan bahwa kuatnya tingkat turnover intention akan diikuti kohesivitas kelompok yang rendah dan sebaliknya, tingkat intensi turnover yang lemah akan diikuti tingkat kohesivitas kelompok yang tinggi.

urnal Manajemen dan Organisasi (JMO),

Vol. 9, No. 1, April 2018, Hal. 35-44 
Selain itu, Septiani (2015) yang meneliti terhadap pemanen kelapa sawit, juga menemukan bahwa kohesivitas kelompok berpengaruh negatif secara signifikan terhadap intensi turnover. Hal tersebut dapat dipengaruhi oleh beberapa faktor seperti kurangnya integrasi kelompok sosial di dalam kelompok panen dan kurangnya ketertarikan pemanen terhadap kelompok panennya. Integrasi kelompok sosial pemanen rendah karena kurangnya waktu untuk melakukan interaksi di kelompok panen.

Selanjutnya, dari hasil uji-t secara tidak langsung antara variabel kohesivitas dan turnover intention diperoleh t-hitung sebesar 4,14. Nilai t-hitung>t-tabel. Berdasarkan nilai estimasi faktor muatan model, kohesivitas berpengaruh negatif secara tidak langsung terhadap turnover intention melalui kepuasan sebesar -0,17, artinya semakin baik kohesivitas maka kepuasan kerja semakin tinggi sehingga dapat menurunkan turnover intention.

\section{KESIMPULAN}

Penelitian ini menemukan pengaruh antara kohesivitas dan kepuasan kerja terhadap turnover intention. Hasil menunjukkan semakin baik kohesivitas karyawan akan semakin meningkatkan kepuasan kerja sehingga dapat menurunkan keinginan karyawan untuk keluar dari perusahaan. Kohesivitas memiliki pengaruh signifikan positif terhadap kepuasan kerja. Dalam hal ini kohesivitas berperan penting dalam meningkatkan kepuasan kerja karena memiliki kelompok yang kohesif akan memengaruhi kepuasan karyawan. Kohesivitas dan kepuasan kerja memiliki pengaruh signifikan negatif terhadap turnover intention. Hal ini menunjukkan kohesivitas dan kepuasan kerja berperan penting dalam menurunkan turnover intention karyawan, meskipun pengaruh kohesivitas terhadap turnover intention lebih kecil dibandingkan pengaruh kepuasan kerja terhadap turnover intention.

Upaya yang dapat dilakukan pihak manajemen PT X untuk meningkatkan kohesivitas dan kepuasan kerja agar dapat mengurangi turnover intention antara lain dengan melaksanakan pelatihan-pelatihan khusus bagi karyawan untuk dapat menghasilkan output kerja yang lebih optimal, pemberian pekerjaan yang menantang, secara berkala melakukan kegiatan yang dapat mendekatkan anggota-anggota divisi agar lebih saling mengenal dan terlibat dengan aktivitas kelompoknya, dan mengevaluasi kembali sistem renumerasi dan sistem insentif karyawan, serta membuka peluang yang sama bagi semua karyawan untuk dipromosikan.

Berdasarkan hasil penelitian, saran yang dapat dipergunakan sebagai bahan penelitian selanjutnya antara lain adalah perlu memperluas objek penelitian pada industri sejenis (farmasi) juga perlu untuk dapat mendapatkan gambaran mengenai tingkat turnover intention karyawan di industri farmasi. Selain itu, dapat juga menambahkan dan menggunakan faktor-faktor yang memengaruhi turnover intention lainnya dalam analisis, seperti kompensasi (insentif) dan komitmen kerja.

Jurnal Manajemen dan Organisasi (JMO),

Vol. 9, No. 1, April 2018, Hal. 35-44

\section{DAFTAR PUSTAKA}

Abdillah F. 2012. Hubungan kohesivitas kelompok dengan intensi turnover pada karyawan. Journal of Social and Industrial Psychology. 1(2):52-58.

Bartkus KR, Howell RD, Parent CRM, Hartman CL. 1997. Managerial antecedents and individual consequences of group cohesiveness in travel service selling. Journal of Travel Research. 56-63.

Carron AV, Widmeyer WN, Brawley LR. 1985. The development of an instrument to assess cohesion in sport teams: the group environment questionnaire. Journal of Sport Psychology. 7:244-266.

Carron AV, Eys MA, Lougheed T, Bray SR. 2009. Development of a cohesion questionnaire for youth: the youth sport environment questionnaire. Sport and Exercise Psychology. $31: 390-408$ 
Colquitt J, Lepine J, Wesson M. 2013. Organization behavior: improving performance and commitment in the workplace. New York (US): McGraw-Hill.

DeCotiis TA, Summers TP. 1987. A path analysis of a model of the antecedents and consequences of organizational commitment. Human Relations. 40(7):445-470.

Elkjaer D, Filmer S. 2015. Trends and drivers of workforce turnover: The result from Mercer's 2014 turnover survey, and dealing with unwanted attrition. Mercer.

Hair JF Jr, Black WC, Babin BJ, Anderson RE. 2010. Multivariate Data Analysis a Global Perspective $8^{\text {th }}$ ed. New Jersey (US): Pearson.

Hapsari A. 2014. Pengaruh kepuasan kerja dan komitmen organisasi terhadap turnover intention pada sales motorist di LTD [tesis]. Bogor (ID): Institut Pertanian Bogor.

Hausknecht JP, Trevor CO, Howard MJ. 2009. Unit-level voluntary turnover rates and customer service quality: implications of group cohesiveness, newcomer concentration, and size. Journal of Applied Psychology. 94(4):1068-1075.

Hom PW, Mitchell TR, Lee TW. 2012. Reviewing employee turnover: focusing on proximal withdrawal states and an expanded criterion. Psychological Bulletin. 138(5):831-858.

Kerr S, Jernier JM. 1978. Subtitutes for leadership: their meaning and measurement. Organizational Behavior and Human Performance. 22:375-403.

Kreitner R, Kinicki A. 2014. Perilaku Organisasi Buku ke-1. Biro Bahasa Alkemis, penerjemah. Jakarta (ID): Salemba Empat. Terjemahan dari: Organizational Behavior. Ed ke-9.

Lum L, Kervin J, Clark K, Reid F, Sirola W. 2016. Explaining nursing turnover intent: job satisfaction, pay satisfaction, or organizational commitment?. Journal of Organizational Behavior. 19(3):305-320.

Mercer. 2016. 2016 Indonesia Turn Over Rate. Jakarta (ID): Mercer Indonesia.

Mobley WH. 2011. Pergantian Karyawan: Sebab-akibat dan Pengendaliannya. Iman N, penerjemah. Jakarta (ID): Pustaka Binaman Pressindo.

Morrison RL. 2008. Negative relationship in the workplace: associations with organizational commitment, cohesion, job satisfaction and intention to turnover. Journal of Management dan Organization. 14(4):330-344.

Mudrack PE. 1989. Group cohesiveness and productivity: a closer look. Human Relations. 42(9):771-785.

Rageb MA, Abd-El-Salam EM, El-Samadicy A, Farid S. 2013. Organizational commitment, job satisfaction and job performance as a mediator between role stressors and turnover intentions a study from an Egyptian cultural perspective. The Business dan Management Review. 3(2):51-73.

Randhawa G. 2007. Relationship between job satisfaction and turnover intentions: an empirical analysis. Indian Management Studies Journal. 11:149-159.

Robbins SP, Judge TA. 2015. Perilaku Organisasi. Saraswati R, Sirait F, penerjemah. Jakarta (ID): Salemba Empat. Terjemahan dari: Organizational Behavior. Ed ke-16.

Septiani R. 2015. Pengaruh kepuasan kerja dan kohesivitas kelompok terhadap intensi turnover pemanen (studi kasus di PT Kencana Sawit Indonesia) [tesis]. Depok (ID): Universitas Indonesia.

Steinhardt MA, Dolbier CL, Gottlieb NH, McCalister KT. 2003. The relationship between hardiness, supervisor support, group cohesion, and job stress as predictors of job satisfaction. American Journal of Health Promotion. 17(6):382-389.

Urien B, Osca A, Garcia-Salmones L. 2016. Role ambiguity, group cohesion and job satisfaction: a demands-resource model (JD-R) study from Mexico and Spain. Revista Latinoamericana de Psicologia. http://dx.doi.org/10.1016/j.rlp.2015.09.014.

Witasari L. 2009. Analisis pengaruh kepuasan kerja dan komitmen organisasional terhadap turnover intention [tesis]. Semarang (ID): Universitas Diponegoro.

Yin-Fah BC, Foon YS, Chee-Leong L, Osman S. 2010. An explanatory study on turnover intention among private sectore employees. International Journal of Business and Management. 5(8):57-64. 
Zhang W, Feng H. 2011. The relationship between job satifaction, burnout, and turnover intention among physicians from urban state-owned medical institutions in Hubei, China: a cross-sectional study. BMC Health Services Researches. 11:235. 